\title{
Baculovirus-Derived HIV-I Virus-Like Particles (VLP) Activate Dendritic Cells and Are Cross-Presented to Induce In Vitro T-Cell Response
}

\author{
L Buonaguro* ${ }^{* 1,3}$, ML Tornesello ${ }^{1}$, E Aricò ${ }^{2}$, FM Marincola ${ }^{2}$, R Lewis- \\ Kamin $^{3,4}$, RC Gallo ${ }^{3}$, GK Lewis ${ }^{3,4}$ and FM Buonaguro ${ }^{1}$
}

\author{
Address: ${ }^{1}$ Viral Oncol. and AIDS Ref. Center, INT "G. Pascale", Naples, Italy, ${ }^{2}$ Immunogen. Lab., Dept. Transf. Med., NIH, Bethesda, MD, USA, \\ ${ }^{3}$ Division of Vaccine Research, IHV, UMBI, MD, USA and ${ }^{4}$ Dept. Microbiol. Immunol., UMB., MD, USA \\ Email: L Buonaguro* - buonoguro@umbi.umd.edu \\ * Corresponding author ‡Presenting author
}

from 2005 International Meeting of The Institute of Human Virology

Baltimore, USA, 29 August - 2 September 2005

Published: 8 December 2005

Retrovirology 2005, 2(Suppl I):S70 doi:I0.I I86/I742-4690-2-SI-S70

\section{Aim}

to evaluate the ability of the baculovirus-expressed HIVVLPA to induce the maturation and activation of monocyte-derived dendritic cells (MDDCs).

\section{Results}

the VLP-activated MDDCs show an enhanced Th1 and Th2-specific cytokine production and the effects of VLPs on MDDCs are, to some extent, mediated through intracellular Toll-like receptors signaling. The VLP-loaded MDDCs are able to induce a primary and secondary response in autologous $\mathrm{T}$ cells, using an in vitro immunization assay. Moreover, the genomic transcriptional profile of VLP-activated DCs show, by gene microarray analysis, the upregulation of several genes involved in the immune response.

\section{Conclusion}

Our results show that baculovirus VLPs activate MDDCs and may "cross" over to the endogenous pathway to gain access to MHC class I, inducing CD8+ cytotoxic T cells activation. The intra-cellular Toll-like receptors appear to be involved in this process; additional signaling pathways induced by VLPs in the MDDCs are currently under evaluation. These data give an insight into the mechanisms of the cellular immunity induced in vivo by VLPs, which may be extremely useful to optimize and modulate the immune response. 